\title{
Precisamos falar sobre evitabilidade dos óbitos fetais no Brasil
}

\author{
We need to talk about avoidability of fetal deaths \\ in Brazil
}

\author{
Precisamos hablar sobre evitabilidad de los \\ óbitos fetales en Brasil
}

Eliane de Freitas Drumond 1

doi: 10.1590/0102-311X00196121

Parabenizo as autoras do excelente artigo Evitabilidade de Óbitos Fetais: Reflexões sobre a Lista Brasileira de Causas de Mortes Evitáveis por Intervenção do Sistema Único de Saúde 1. No artigo, as autoras respondem de forma clara e objetiva a desafiadora tarefa de propor uma revisão da Lista Brasileira de Causas de Mortes Evitáveis (LBE) com foco nos óbitos fetais (LBE-OF) 2,3. Assim, jogam luz sobre a importância da abordagem desses óbitos sob o prisma da evitabilidade. Infelizmente, óbitos fetais tendem a ser invisibilizados no Brasil - onde paradoxalmente parece haver enorme preocupação sobre o controle do corpo da mulher no que se refere ao direito ao aborto.

Além de parabenizar as autoras, gostaria de propor algumas reflexões sobre tão importante tema de saúde pública no Brasil: os óbitos fetais e sua evitabilidade por ações dos serviços de saúde. Entre os resultados que apontam para a adequação das realocações de causas propostas pelo estudo destaca-se o elevado percentual $(43,6 \%)$ de óbitos devido a causas reduzíveis por adequada atenção à mulher na gestação, o que vai de encontro a achados de inúmeros trabalhos nacionais que evidenciam a relevância do pré-natal em número e qualidade adequados na redução das mortes perinatais e neonatais, além das mortes maternas. Destaca-se também o elevado percentual obtido pelo grupo de causas mal definidas $(35,4 \%)$ - ao qual foi corretamente incluído "hipóxia intrauterina não especificada", refletindo provável persistência de omissão das menções das causas maternas na sequência de eventos que levou ao óbito fetal, provavelmente mesmo nos cerca de $80 \%$ de casos investigados. Esse achado reforça a necessidade de ações voltadas à melhoria da qualidade das investigações das causas de morte fetais/perinatais.

Finalmente, mas de fundamental importância, coloca-se a discussão sobre as vantagens/desvantagens da seleção dos casos baseada na idade gestacional ( $\geq 22$ semanas e idade gestacional ignorada) como adotado no presente estudo - ou, alternativamente, no peso ao nascer ( $\geq 500 \mathrm{~g}$ e peso ignorado), dado que ambas as condições são definidoras dos óbitos fetais 4 . A falta de padronização para o cálculo, o percentual de ignorados (6,9\% no presente estudo), a concordância apenas regular com o "padrão ouro" - obtida em estudo brasileiro (com tendência a subestimação da idade) - e a maior dificuldade de sua correção por investigadores seriam desvantagens da utilização da idade gestacional 5. Por sua vez, de forma vantajosa, o peso ao nascer tem menor porcentagem de ignorados (4,5\%, segundo dados disponibilizados pelo Departamento de Informática do SUS; http://tabnet.datasus.gov.br/cgi/tabcgi. exe?sim/cnv/fet10rj.def, acessado em 05/Ago/2021), é medida objetiva e padronizada, pode ser mais
1 Registro Hospitalar de Câncer, Instituto Mario Penna, Belo Horizonte, Brasil.

\section{Correspondência} E. F. Drumond Rua Dona Cecília 500, Belo Horizonte, $M G$ 30320-070, Brasil. elianedrumond1d@gmail.com 
facilmente obtido e corrigido pelas equipes de investigação. A utilização do peso ao nascer, além de contribuir na definição do potencial de evitabilidade (como ressaltam as autoras), manteria na LBE-OF as características que facilitam e possibilitam o uso da LBE em todo o país: regras claras, facilmente aplicáveis além de dados de fácil acesso no Sistema de Informações sobre Mortalidade (SIM).

\section{Informação adicional}

ORCID: Eliane de Freitas Drumond (0000-00032159-4250).
1. Fonseca SC, Kale PL, Teixeira GHMC, Lopes VGS. Evitabilidade de óbitos fetais: reflexões sobre a Lista Brasileira de Causas de Mortes Evitáveis por intervenção do Sistema Único de Saúde. Cad Saúde Pública 2021; 37:e00265920.

2. Malta DC, Duarte EC. Causas de mortes evitáveis por ações efetivas dos serviços de saúde: uma revisão da literatura. Ciênc Saúde Colet 2007; 12:765-76.

3. Malta DC, Sardinha LMV, Moura L, Lansky S, Leal MC, Szwarcwald CL, et al. Atualização da lista de causas de mortes evitáveis por intervenções do Sistema Único de Saúde do Brasil. Epidemiol Serv Saúde 2010; 19:173-6.

4. Secretaria de Vigilância em Saúde/Secretaria de Atenção à Saúde, Ministério da Saúde. Manual de vigilância do óbito infantil e fetal e do Comitê de Prevenção do Óbito Infantil e Fetal. 2a Ed. Brasília: Ministério da Saúde; 2009.

5. Rodrigues PL, Gama SGN, Mattos IE. Completitude e confiabilidade do Sistema de Informações sobre Mortalidade para óbitos perinatais no Brasil, 2011-2012: um estudo descritivo. Epidemiol Serv Saúde 2019; 28:e2018093.

Recebido em 06/Ago/2021

Aprovado em 13/Ago/2021 